Article

\title{
Analysis of Learning Motivation in Industrial Engineering Teaching in University of Extremadura (Spain)
}

\author{
Gonzalo Sánchez-Barroso ${ }^{1}{ }^{(D)}$, Jaime González-Domínguez ${ }^{1}$ [D, Justo García-Sanz-Calcedo ${ }^{1, *(1)}$ \\ and Francisco Zamora-Polo ${ }^{2}$ (D) \\ 1 Industrial Engineering School, University of Extremadura, 06007 Badajoz, Spain; gsm@unex.es (G.S.-B.); \\ jaimegd@unex.es (J.G.-D.) \\ 2 Dpto. Ingeniería del Diseño, Escuela Politécnica Superior, Universidad de Sevilla, Virgen de África, 7, \\ 41011 Sevilla, Spain; fzpolo@us.es \\ * Correspondence: jgsanz@unex.es; Tel.: +34-924-289-300
}

Received: 6 May 2020; Accepted: 15 June 2020; Published: 18 June 2020

\begin{abstract}
Motivational orientations predispose and condition behaviour, and determine the degree of assimilation of concepts by students during their training stage. Knowing them allows professors to conduct their lessons in order to favour maximum achievement for students. The objective of this work is to evaluate the motivation that guides the learning process of Industrial Engineering students at the University of Extremadura (Spain). About three quarters of the students present a high motivation for learning; half of them tend to be result-oriented and less than $10 \%$ show a high level of fear of failure. Homogeneous groups were formed based on the level of each dimension, and influential teaching methodologies were discussed. Therefore, it is possible to create a context that favors the acquisition of knowledge by students according to their motivations, and thus achieve maximum academic performance from them. The results shown here may be interesting for the design of promotional activities for SDGs in the university context.
\end{abstract}

Keywords: motivation; higher education; industrial engineering; teaching; engineering education; SDG

\section{Introduction}

Motivation is the engine that drives all behaviour, generating a series of changes, both academically and personally. Motivation is made up of a very diverse set of factors, which can be personal and contextual, and involves a multitude of processes that lead to the activation, direction and persistence of a behaviour [1].

In the educational field, among other complementary objectives, the assimilation of concepts by students is intended, so that they shape their theoretical and practical knowledge of certain subjects. In a context where the ultimate goal is to learn, various factors converge that influence, to a greater or lesser extent, the very outcome of learning [2]. Carrillo et al. [3] analyzed the concepts of motivation and learning, as well as the mutual implications between them. They identified a series of teaching interventions that favour student motivation and described how they generate a certain type of learning.

The relationship between motivation during learning and academic performance involves a number of inter-related issues [4]. This academic performance is influenced by the student's effort output, work capacity and involvement in the process [5]. In a simplistic approach, the reasoning might state that a demotivated student will get bad grades, while the opposite is true for a motivated student. In practical reality, the relationship between the two is not so direct and simple, because there 
are different "types" of motivations that are initiated, depending on the context or the objective pursued, for example. Romero-García defined motivation as a series of "internal states that energize and direct behavior towards specific goals" [6]. For his part, Singh concluded that motivation creates self-determination and a feeling of enthusiasm that leads a student to make a greater effort in personal and academic processes [7].

Studies such as Firat et al. [8] determined the intrinsic motivation level of open- and distance-learning students, collecting data from 1639 students enrolled in 22 programs. They found that the level of intrinsic motivation of these students was high in e-learning environments, but there is no statistically significant difference by gender, program structure (undergraduate/graduate), type of instruction and academic disciplines.

On the other hand, Wang built a theoretical framework for understanding motivations [9], subjects and context that drive high school students to choose careers in science, technology, engineering and mathematics (STEM). The results show that students who are aware that they have demonstrated adequate math skills in previous courses are more likely to enroll in a STEM career. Numerous studies attempt to justify the widespread rejection of mathematics [10,11]. A relationship/connection could then be established between being aware of possessing adequate mathematical abilities and having a motivational orientation to learning, as understood by this dimension. This reasoning leads to the hypothesis that this motivation prevails among the engineering students that are the object of this study.

Previous works have been carried out on the motivations of the students to select the modality of study in high school, access to the university $[12,13]$ and the internal and external motivations of university students [14].

There is a growing interest in introducing aspects of sustainable human development into engineering studies $[15,16]$. The United Nations has proposed a work agenda for the time horizon 2015-2030 called Sustainable Development Goals (SDGs) [17]. A crucial aspect for the achievement of the SDGs is to address them in higher education institutions [18-21]. In a recent paper, a framework for the development of SDGs has been proposed [21]. This framework is made up of five dimensions: the students, the competences that they must develop, the methodology to be implemented, the training of the professors and the creation of alliances. In this context, it is essential to know what the needs of the students are, as well as the ultimate motivations for their study. In this way, training activities for the promotion of sustainability and the achievement of the SDGs can be planned more effectively.

On the other hand, active teaching methodologies such as gamification, flipped classroom class or project-based learning are now a trend [2,22-24]. These methodologies create a positive emotional performance [25,26], develop both specific and transversal competences [2] and increase students' motivation $[2,22-24,27]$.

Analyzing and knowing the motivations of students can lead to a significant improvement in the quality of education [28]. This study aims to analyze the motivational trends that converge in students, as well as the specific motivations that move university students of Industrial Engineering at the University of Extremadura, with the purpose of proposing/discussing strategies of educational intervention that improve their academic performance and designing future interventions to promote SDGs in university studies.

\section{Methodology}

To carry out this analysis, the MAPE-II instrument was used [29], which assesses student motivation by directing it towards three motivational orientations: motivation to learn, motivation to succeed and fear of failure. There are six specific motivations (or scales) that constitute the so-called first-order factors of these motivations: high work capacity and performance (Sc. 1), intrinsic motivation (Sc. 2), laziness (Sc. 3), ambition (Sc. 4), anxiety enabling performance (Sc. 5) and anxiety inhibiting performance (Sc. 6). The scales (Sc. 1), (Sc. 2) and (Sc. 6) make up the first dimension (Dim. 1), (Sc. 3) and (Sc. 5) the 
second (Dim. 2), and (Sc. 4) only the third (Dim. 3). All survey questions and evaluation criteria are available to the reader at: http://sohs.pbs.uam.es/webjesus/publicaciones/castellano/cap6.pdf.

Fifty-eight surveys were collected from randomly selected students of both sexes (50 males and eight females) aged 21-24, enrolled in the last year of the Engineering Degree at the University of Extremadura (Spain) during the 2018-2019 academic year. The data were collected anonymously and each student was coded with a number (1-58) indicating the order in which their results were recorded.

Questionnaire responses were scored according to MAPE-II instructions, thus calculating the direct scores of the scales and, subsequently, of the dimensions. These were then transformed into percentiles according to the tables provided in MAPE-II. Depending on the percentile assigned to each student in each scale and dimension, they were classified into three levels that coincided with the following quartiles: low $\left(\mathrm{Q}_{1}\right)$, medium $\left(\mathrm{Q}_{2}-\mathrm{Q}_{3}\right)$ and high $\left(\mathrm{Q}_{4}\right)$.

IBM SPSS Statistics 25 [30] statistical software was used to perform the statistical tests and analyses described below.

First, the internal consistency of the instrument used was checked. The reliability check was carried out to verify the consistency of the data collection. It was performed using the KR-20 Test, which is a Cronbach's alpha variant for dichotomous variables [31]. An alpha value greater than 0.7 will be taken as acceptable. This criterion can be relaxed taking into account that the instrument used (MAPE-II) is already validated.

It was then checked whether there was a correlation between percentiles of each student for specific motivations and between dimensions, in order to establish internal relationships between the first-order motivations and between the second ones. Pearson's correlation coefficient with a significance level of 0.05 was used [32]. Subsequently, it was checked if there is a significant difference between the scores of males and females.

Finally, a hierarchical cluster analysis was carried out to establish groups of people with similar motivational characteristics. An agglomerative algorithm based on Ward's method was used to perform the clustering [33].

\section{Results}

\subsection{Internal Consistency of the Instrument}

Analysis of students' response patterns to the survey indicates, on the one hand, an average reliability of the first-order scales of 0.734 (range between 0.637 and 0.797 ). On the other hand, the reliability of the second order factors ranges from 0.759 to 0.783 , with an average reliability of 0.771 .

\subsection{Scores}

The distributions of the scales' scores shown in Figure 1 were obtained from the calculation of the direct score of the scales (first order factors).

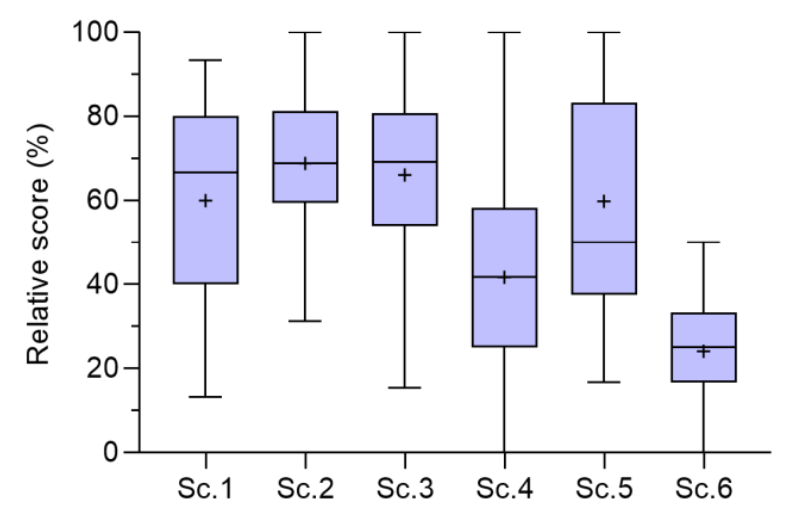

Figure 1. Distributions of the scales' relative scores. 
Intrinsic motivation (Sc. 2) is the scale that stands out most among the students surveyed, reaching the highest relative average score ( $11 \pm 2.7$ out of 16 possible points). On the opposite side, laziness (Sc. 6) is the least outstanding, with the lowest average relative score $(2.9 \pm 1.5$ out of 12 possible points). Ambition (Sc. 3) is the next most outstanding, with an average score of 8.6 (deviation of 2.6) out of 13 available points. The specific motivations of high work capacity (Sc. 1) and performance and anxiety enabling performance (Sc. 5) achieve similar scores, with an average of $9 \pm 3.5$ points (15 possible) and $7.2 \pm 3.2$ points (12 available), respectively. Anxiety inhibiting performance (Sc. 4 ) is the second least present scale among students with an average of 5 out of 12 points (deviation of 2.8 points).

The direct score of the dimensions (secondary factors) is obtained by aggregating the direct score of the scales. The distribution of the dimension scores is shown in Figure 2.

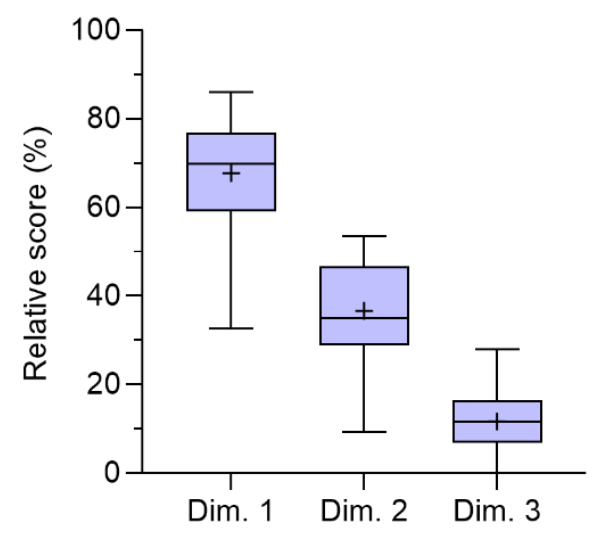

Figure 2. Distributions of the dimensions' relative scores.

The predominant dimension among students is motivation for learning with an average of $29.1 \pm 5.5$ points (out of 43 possible), followed by motivation for the result which has an average value of $15.8 \pm 4.9$ points (out of 25 available), and finally fear of failure with an average of 5 points (deviation of 2.8 points) out of 12 possible.

\subsection{Percentiles}

The distribution of students in each dimension according to the levels associated with their percentile is shown in Table 1.

Table 1. Distribution of students in levels by motivational orientations.

\begin{tabular}{ccccccc}
\hline \multirow{2}{*}{ Dimensions } & \multicolumn{9}{c}{ Levels } \\
\cline { 2 - 8 } & \multicolumn{2}{c}{ High } & \multicolumn{2}{c}{ Medium } & \multicolumn{2}{c}{ Low } \\
\cline { 2 - 8 } & $\mathbf{N}$ & $\mathbf{N}$ & $\mathbf{N}$ & $\mathbf{N}$ & $\%$ \\
\hline Motivation to learn & 42 & $72.4 \%$ & 14 & $24.1 \%$ & 2 & $3.5 \%$ \\
Motivation to results & 30 & $51.7 \%$ & 26 & $44.8 \%$ & 2 & $3.5 \%$ \\
Fear to failure & 12 & $20.7 \%$ & 28 & $48.3 \%$ & 18 & $31.0 \%$ \\
\hline
\end{tabular}

It is observed that just two of the respondents show low motivation for learning, while the vast majority $(72.4 \%)$ show high motivation for learning $\left(\mathrm{Q}_{4}\right)$. The same occurs for results motivation, with only two individuals who have a low motivation. It should be noted that these are not the same people as before. In this case, the rest of the sample is distributed almost equally between high $(51.7 \%)$ and medium result motivation $(44.8 \%)$. High fear of failure $\left(\mathrm{Q}_{4}\right)$ is present in $20 \%$ of the sample and a low level $\left(\mathrm{Q}_{1}\right)$ of this dimension is in $31 \%$. Almost half of the sample has a medium level of fear of failure. 
The distribution of students in each level of the scale is as shown in Table 2.

Table 2. Distribution of students in levels by specific motivations.

\begin{tabular}{ccccccc}
\hline & \multicolumn{5}{c}{ Levels } \\
\cline { 2 - 7 } Dimensions & \multicolumn{2}{c}{ High } & \multicolumn{2}{c}{ Medium } & \multicolumn{2}{c}{ Low } \\
\cline { 2 - 7 } & $\mathbf{N}$ & $\%$ & $\mathbf{N}$ & $\%$ & $\mathbf{N}$ & $\%$ \\
\hline High capacity for work and performance & 38 & $64.4 \%$ & 20 & $34.5 \%$ & 0 & $0.0 \%$ \\
Intrinsic motivation & 20 & $34.5 \%$ & 32 & $55.2 \%$ & 6 & $10.3 \%$ \\
Ambition & 22 & $37.9 \%$ & 34 & $58.5 \%$ & 2 & $3.5 \%$ \\
Anxiety inhibiting performance & 12 & $20.7 \%$ & 28 & $48.3 \%$ & 18 & $31.0 \%$ \\
Anxiety enabling performance & 26 & $44.8 \%$ & 24 & $42.4 \%$ & 8 & $13.8 \%$ \\
Laziness & 4 & $6.9 \%$ & 46 & $79.3 \%$ & 8 & $13.8 \%$ \\
\hline
\end{tabular}

In general, an average of $52.8 \%$ of the students are in the middle level of each scale, followed by an average of $35.1 \%$ in the high level and the remaining $12.1 \%$ in the low level. Due to the character (positive or negative) of each scale, it is necessary to analyze the distribution of the subjects individually, since it is not the same to have a high level of intrinsic motivation as having the same level for anxiety inhibiting performance.

It should be noted that there is no respondent with a low level of high work capacity and performance, and that most of them $(64.4 \%)$ have a high level $\left(\mathrm{Q}_{4}\right)$ of this specific motivation. Slightly more than half of the students $(55.2 \%)$ are in the medium level $\left(Q_{2}-Q_{3}\right)$ of intrinsic motivation, followed by $34.5 \%$, who are in the high level $\left(\mathrm{Q}_{4}\right)$.

On the contrary, it is worth mentioning that almost a fifth of the class $(20.7 \%)$ has a high level of anxiety inhibiting performance, as opposed to the third of the total $(31.0 \%)$, which is at the low level. However, the results for anxiety facilitating performance are $44.8 \%$ in the high level and $13.8 \%$ in the low level. Only $6.9 \%$ of the students are at a high level of laziness and the majority of those surveyed $(79.3 \%)$ are at a medium level. Just over a third of the class $(37.9 \%)$ has a high level of ambition, while just over half (58.5\%) has a medium level of this scale.

\subsection{Correlations among Scales and among Dimensions}

For a significance level of 0.05 , we find that there are two pairs of specific correlated motivations. First, high work capacity and performance and intrinsic motivation have a Pearson's correlation coefficient of 0.738 . Second, laziness is correlated with performance-facilitating anxiety, with a coefficient of 0.733 . The rest of the relationships between basic scales are not significant and the correlation coefficients between them do not exceed 0.3. In turn, no significant correlation is detected between motivational orientations.

\subsection{Students' Motivation}

It is noteworthy that no differences were found in learning motivation between males and females or between age groups. Table 3 shows the level of motivational orientations of each student, according to the above-described quartile distribution. In this way, it is possible to analyze how the levels of the dimensions in each person are combined and what the trends in the class are.

The most negative situation is found, on the one hand, in those individuals (no. 9, 22, 26 and 36) who are not highly motivated by learning or results and, moreover, have a medium or low fear of failure. On the other hand, we can initially think of those individuals who had low motivation for learning (no. 28 and 41), however, this is combined with a high motivation for results and an average tolerance for failure. It occurs in a similar way in the two who had low motivation for results (no. 1 and 40), however, it shows a high motivation for learning and low fear of failure. On the other hand, high fear of failure is mostly combined with high motivation for learning ( 8 out of 12). It is also detected with high result motivation (2 of 12) and with high motivation in both motivations (2 of 12). 
Table 3. Distribution of students in levels by specific motivations.

\begin{tabular}{|c|c|c|c|}
\hline \multirow{2}{*}{ Levels } & \multicolumn{3}{|c|}{ Dimensions } \\
\hline & Motivation to Learn & Motivation to Results & Fear of Failure \\
\hline High & $\begin{array}{c}1,2,3,6,7,8,10,11,13,15,18, \\
19,20,21,23,24,27,29,20,32, \\
33,34,35,37,38,39,40,42,43, \\
44,45,46,48,49,50,51,52,53, \\
55,56,57,58\end{array}$ & $\begin{array}{c}4,2,5,7,10,12,13,14,15 \\
16,17,21,23,24,25,28 \\
29,30,31,35,38,39,41 \\
47,49,52,54,56,57,58\end{array}$ & $\begin{array}{c}5,6,8,11,17,18,32 \\
43,50,52,55,56\end{array}$ \\
\hline Medium & $\begin{array}{c}4,5,9,12,14,16,17,22,25,26 \\
31,36,47,54\end{array}$ & $\begin{array}{c}3,6,8,9,11,18,19,20,22 \\
26,27,32,33,34,36,37 \\
42,43,44,45,46,48,50 \\
51,53,55\end{array}$ & $\begin{array}{c}4,2,3,7,10,12,15, \\
16,20,21,22,23,26, \\
27,28,29,30,33,34, \\
37,38,39,41,42,47, \\
49,53,57\end{array}$ \\
\hline Low & 28,41 & 1,40 & $\begin{array}{c}1,9,13,14,19,24 \\
25,31,35,36,40,44 \\
45,46,48,51,54,58\end{array}$ \\
\hline
\end{tabular}

For those with a high percentile in learning and results, this is often combined with a fear of failure at the middle level (12 of the 18 in this case). The four cases with a low level of fear of failure are worth noting. Speaking of those who have a high motivation only for learning (16), this is usually combined with a medium motivation for results (14) and with a medium-low fear of failure. There are cases that have already been mentioned, which combine with a high level of fear of failure. It remains to be commented that eight of the ten cases that only show a high motivation for results, have a medium motivation for learning and low motivation in the last two cases. Furthermore, they combine with low (4), medium (4) and high (2) levels of fear of failure.

These groups have been broadly outlined by linking together those cases that show a similar pattern of motivation. Figure 3 shows a dendrogram in which different groups of cases are formed according to the distance between them.

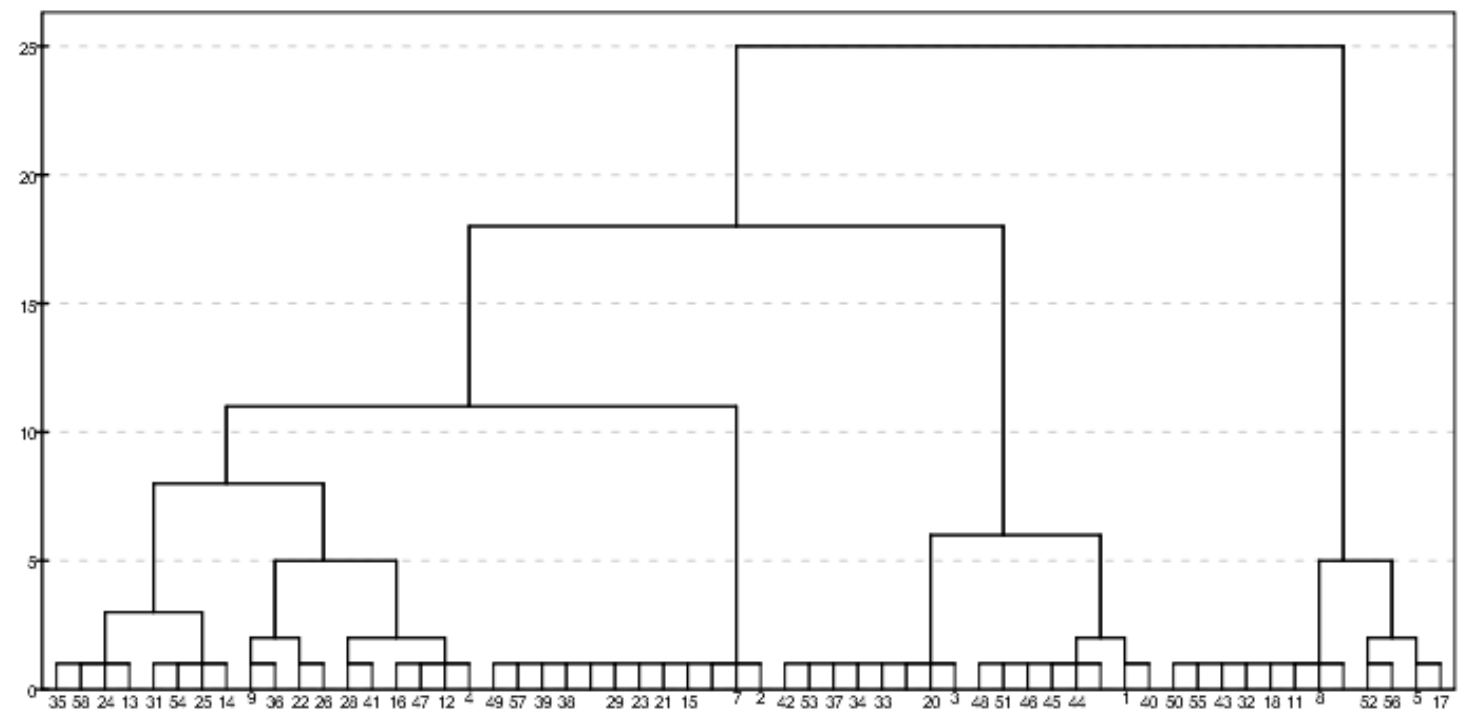

Figure 3. Cluster dendrogram according to degree of dissimilarity and case groupings according to level of each dimension: low (L), medium (M) and high $(\mathrm{H})$.

As the distance increases, the dissimilarity between the elements increases. The criterion for constructing this graph consists of joining those cases in groups (clusters) so that they are as internally homogeneous as possible and as heterogeneous as possible between them. Taking as valid a distance between groups of value 5 , which is considered an acceptable value of similarity over the total distance of 
25 , eight groups of people with similar motivational orientations would be formed in the class. For this degree of similarity, the clusters that have been formed coincide at the two-dimensional level and, if there is a different one, it will only group the adjacent ones (low-medium or medium-high). The level assigned to each dimension that characterizes the clusters formed is indicated in the left margin.

\section{Discussion}

In order to carry out intervention actions in the classroom that have a positive impact on learning, the motivational orientation of the student must be evaluated, but also the specific goals that make up these dimensions [14].

A large proportion of students have been found to be predominantly learning-oriented. Confirming this assumption is enormously positive for students, since it allows them to be in a continuous process of acquiring skills and the knowledge that underlies them [34]. Another large proportion is directed at the results-oriented dimension. Undoubtedly, this motivation is an enormous quality of engineers. However, this implies a short-term vision in the educational environment that will be more appropriate during the working stage than during the training stage [35]. Addressing oneself solely on the basis of this motivation is likely to have a negative impact on one's future professional performance due to the lack of robustness of the knowledge acquired and the unwillingness to acquire new knowledge [36]. However, it has been found that the two are generally complementary, which provides an ideal framework for the acquisition of knowledge and its materialization into acceptable results. Motivational orientations are not exclusive, and may change depending on the conditions in which we must work, as highlighted in [37].

The process of forming groups of students according to the levels of specific motivations would not lead to a useful solution for deciding on appropriate teaching methodologies. This is because there are six scales that are further divided into three levels, resulting in numerous combinations that would form groups of very few students, which is not practical.

In this sense, it could be highlighted that the distribution of students for the anxiety enabling performance and anxiety inhibiting performance scales are not complementary, as could be thought a priori. The explanation for this phenomenon lies in the context, so that, for the same person, there are situations of stress or pressure that favour their effort and others that reduce their performance [38]. This phenomenon has to do with knowledge and self-regulation, in the sense that the student, faced with a certain situation, is aware of his possibilities of success, derived from the knowledge he/she possesses, and how he/she behaves (self-regulates), knowing that he/she does not have the appropriate skills [34]. However, evaluating these factors is beyond the scope of this study.

At this point, it is necessary to reflect on the characteristics or conditions that the learning context should present in order to achieve the maximum performance of the learners, taking into account their motivations. That is to say, to make decisions of intervention in the classroom, by means of which the strategy of exposition of contents is defined, the type of activity that demands the participation of the students, the learning objectives, etc. All of this is done with the aim of preventing the student from having a passive role in and/or out of the classroom that negatively influences the assimilation of content [39]. To do so, it is necessary to develop motivational strategies aimed at both awakening the student's interest in a given subject, as well as stimulating his/her desire to learn about the subject and to direct his/her attention and effort towards the area of the contents studied [40]. In this sense, active teaching-learning methodologies can have a positive and motivating effect on students [2,22,27].

In this work we have managed to synthesize the class into eight groups of students with a predominance of identical (or almost identical) dimensions. The heterogeneity of the results obtained does not help to define a common teaching methodology for the whole class. It invites the segregation of these groups of few components so that certain teaching strategies can be focused on to favour their learning. This idea coincides with the current trend of fragmenting the class to form work teams [41] Nevertheless, the benefits of the criteria for forming groups should be assessed, in order to determine 
whether they should be homogeneous and composed of people with similar motivational orientations, or, on the contrary, heterogeneous.

Homogeneous groups allow the application of specific teaching methodologies for their learning motivations, but do not foster an enriching environment in which students complement each other to form a joint result [42] The latter is the main advantage of heterogeneous groups; however, it prevents directing specific activities according to the motivation that characterizes the group. The balance between these statements lies in the choice of one or the other, according to the tasks programmed at each stage of the learning process.

The results shown here can be used for the implementation of innovative activities in university classrooms. Previous studies have shown the motivating effect of university experiences such as gamification [23], Problem-Based Learning [24] and flipped classroom [43]. Thus, Buckley and Doyle showed that gamification in virtual environments had a positive effect on student motivation, although results varied depending on prior motivation [23]. In the same vein, Terrón-López et al. [24] showed that a project-based learning experience developed at the European University of Madrid improved students' motivation in the field of engineering. By developing capstone projects, they increased the motivation of both teachers and students. Finally, Park et al. found that students' motivations are influenced by the type of activity performed; in their case, they analyzed whether the activities were carried out in an individual or multidisciplinary manner [43].

This work is part of a broader line of work for the development of transversal skills in engineering degrees, and in particular for the promotion of sustainability and the Sustainable Development Goals [44]. In a recent paper, a framework was proposed that emphasized the importance of knowing students in the design of activities to promote the Objectives of Sustainable Development in the university [21]. In this way, knowing what the previous motivations of students are can be fundamental for the correct design of the activities that are programmed, as well as for evaluating if the development of the same has been of a motivating character or not.

Future work should be oriented towards checking whether the results can be extrapolated to other qualifications in the technical branch.

\section{Conclusions}

In this work, an in-depth exploratory analysis of the specific (basic) motivations and motivational orientations of a group of students belonging to the same Industrial Engineering class has been carried out. In spite of using an empirically validated instrument, the internal consistency of the tool has been checked, validating the results.

The results show that two thirds of the class have a high level of work ability and performance; one third also falls within the high level of intrinsic motivation and ambition, and almost half rises to the high level of anxiety inhibiting performance. In contrast, it is notable that almost half of the students have a medium level of anxiety enabling performance and almost $80 \%$ rated as a medium level of laziness. Nearly three quarters of the students show a high motivational orientation towards learning, slightly more than half tend to be results-oriented, and only about $7 \%$ show a high level of fear of failure.

This work is useful to intervene in the educational process, creating a context in the classroom that promotes the acquisition of knowledge by students according to their motivations, and thus achieve their maximum academic performance. The work presented here is the baseline on which to design student-centered learning activities to promote sustainability and Sustainable Development Goals at university level.

The results shown here are preliminary and should be compared with a larger sample of students. In the future, it is intended to develop research that analyses the modification of student motivation towards innovative activities such as project-based learning or gamification. We hope that students' prior knowledge will allow for a more effective design of these interventions. 
Author Contributions: Conceptualization, J.G.-S.-C. and F.Z.-P.; Data curation, G.S.-B.; Formal analysis, G.S.-B. and J.G.-D.; Investigation, G.S.-B. and J.G.-S.-C.; Methodology, F.Z.-P.; Resources, J.G.-D.; Software, G.S.-B.; Supervision, J.G.-S.-C.; Validation, J.G.-S.-C. and F.Z.-P.; Visualization, J.G.-D. All authors have read and agreed to the published version of the manuscript.

Funding: This research was funded by VI Regional Research, Technological Development and Innovation Plan of the General Government of Extremadura, grant number GR-18029 through European Regional Development Fund.

Acknowledgments: The authors wish to express their gratitude to the Regional Government of Extremadura, and the European Regional Development Fund for support this research.

Conflicts of Interest: The authors declare no conflict of interest.

\section{References}

1. Palmero, F. Motivación: Conducta y proceso. Rev. Electrón. Motiv. Emoc. 2005, 8, 1-29.

2. Zamora-Polo, F.; Martínez Sánchez-Cortés, M.; Reyes-Rodríguez, A.M.; García-Sanz-Calcedo, J. Developing Project Managers' Transversal Competences Using Building Information Modeling. Appl. Sci. 2019, 9, 4006. [CrossRef]

3. Carrillo, M.; Padilla, J.; Rosero, T.; Villagómez, M.S. La motivación y el aprendizaje. ALTERIDAD Rev. Educ. 2009, 4, 20-32. [CrossRef]

4. Beamud González, E.M.; Núñez López, P.J.; García Plaza, E.; Rodríguez Salgado, D.; González González, A.; Garcia-Sanz-Calcedo, J.G. Reverse Engineering Applied to the Teaching of Computer Aided Manufacturing. Mater. Sci. Forum 2017, 903, 120-127. [CrossRef]

5. Joseph, R.D.B.; Pal, A.; Tunks, J.; Mehta, G. Intrinsic vs. Extrinsic Motivation in an Interactive Engineering Game. J. Adv. Comput. Eng. Technol. 2019, 5, 37-48.

6. Romero-García, O. Motivando Para el Trabajo; Cuadernos Lagoven, Serie Siglo XXI: Caracas, Venezuela, 1985.

7. Singh, K. Study of Achievement Motivation in Relation to Academic Achievement of Students. Int. J. Educ. Plan. Adm. 2011, 1, 161-171.

8. Fırat, M.; Kılınç, H.; Yüzer, T.V. Level of intrinsic motivation of distance education students in e-learning environments. J. Comput. Assist. Learn. 2018, 34, 63-70. [CrossRef]

9. Wang, X. Why Students Choose STEM Majors. Am. Educ. Res. J. 2013, 50, 1081-1121. [CrossRef]

10. Dowker, A.; Sarkar, A.; Looi, C.Y. Mathematics Anxiety: What Have We Learned in 60 Years? Front. Psychol. 2016, 7. [CrossRef]

11. Castro, E.J.; Miranda, I. Experiencias Desmotivacionales y Motivacionales de Estudiantes Varones de Ingeniería para Estudiar Matemáticas. El Caso de la Universidad Andrés Bello en Santiago de Chile. Form. Univ. 2019, 12, 83-92. [CrossRef]

12. Corrales-Serrano, M.; Sánchez-Martín, J.; Moreno-Losada, J.; Zamora-Polo, F. Motivations of young people for the study: Roots and consequences. Cuad. Investig. Juv. 2018, 4, e020.

13. Corrales-Serrano, M. Estudio de las Motivaciones Internas y Externas para la Elección de Modalidad del Alumnado de Bachillerato. Incidencia en la Didáctica de las Ciencias Sociales; University of Extremadura: Extremadura, Spain, 2020.

14. Moreno-Losada, J. Estudio "con-Sentido" en la Universidad. Motivación del Estudio en los Universitarios Extremeños y el Bien Interno de las Profesiones; University of Extremadura: Extremadura, Spain, 2015.

15. Pérez-Foguet, A.; Lazzarini, B.; Giné, R.; Velo, E.; Boni, A.; Sierra, M.; Zolezzi, G.; Trimingham, R. Promoting sustainable human development in engineering: Assessment of online courses within continuing professional development strategies. J. Clean. Prod. 2018, 172, 4286-4302. [CrossRef]

16. Lazzarini, B.; Pérez-Foguet, A.; Boni, A. Key characteristics of academics promoting Sustainable Human Development within engineering studies. J. Clean. Prod. 2018, 188, 237-252. [CrossRef]

17. General Assembly of United Nations Transforming our world: The 2030 Agenda for Sustainable Development. Resolution adopted by the General Assembly on 25 September 2015. Available online: http://www.un.org/ ga/search/view_doc.asp?symbol=A/RES/70/1\&Lang=E (accessed on 7 November 2018).

18. Boni, A.; Lopez-Fogues, A.; Walker, M. Higher education and the post-2015 agenda: A contribution from the human development approach. J. Glob. Ethics 2016, 12, 17-28. [CrossRef]

19. Lazzarini, B.; Pérez-Foguet, A. Profiling research of the engineering academics who successfully promote education in Sustainable Human Development. J. Clean. Prod. 2018, 172, 4239-4253. [CrossRef] 
20. Zamora-Polo, F.; Sánchez-Martín, J.; Corrales-Serrano, M.; Espejo-Antúnez, L. What Do University Students Know about Sustainable Development Goals? A Realistic Approach to the Reception of this UN Program Amongst the Youth Population. Sustainability 2019, 11, 3533. [CrossRef]

21. Zamora-Polo, F.; Sánchez-Martín, J. Teaching for a Better World. Sustainability and Sustainable Development Goals in the Construction of a Change-Maker University. Sustainability 2019, 11, 4224. [CrossRef]

22. Sánchez-Martín, J.; Cañada-Cañada, F.; Dávila-Acedo, M.A. Just a game? Gamifying a general science class at university: Collaborative and competitive work implications. Think. Ski. Creat. 2017, 26, 51-59. [CrossRef]

23. Buckley, P.; Doyle, E. Gamification and student motivation. Interact. Learn. Environ. 2016, 24, $1162-1175$. [CrossRef]

24. Terrón-López, M.-J.; García-García, M.-J.; Velasco-Quintana, P.-J.; Ocampo, J.; Vigil Montaño, M.-R.; Gaya-López, M.-C. Implementation of a project-based engineering school: Increasing student motivation and relevant learning. Eur. J. Eng. Educ. 2017, 42, 618-631. [CrossRef]

25. Jeong, J.; Cañada-Cañada, F.; González-Gómez, D. The Study of Flipped-Classroom for Pre-Service Science Teachers. Educ. Sci. 2018, 8, 163. [CrossRef]

26. Jeong, J.S.; González-Gómez, D.; Cañada-Cañada, F.; Gallego-Picó, A.; Bravo, J.C. Effects of active learning methodologies on the students' emotions, self-efficacy beliefs and learning outcomes in a science distance learning course. J. Technol. Sci. Educ. 2019, 9, 217. [CrossRef]

27. Lassen, A.K.; Hjelseth, E.; Tollnes, T. Enhancing learning outcomes by introducing BIM in civil engineering studies-Experiences from a university college in Norway. Int. J. Sustain. Dev. Plan. 2018, 13, 62-72. [CrossRef]

28. Maquilón Sánchez, J.J.; Hernández Pina, F. Influencia de la motivación en el rendimiento académico de los estudiantes de formación profesional. REIFOP 2011, 14, 81-100.

29. Montero, I.; Alonso Tapia, J. El cuestionario MAPE-II. In Motivar en la Adolescencia: Teoría, Evaluación e Intervención; Servicio de Publicaciones de la Universidad Autónoma de Madrid: Madrid, Spain, 1992; pp. 205-231. ISBN 84-7477-414-4.

30. IBM Corp. IBM Statistics, 25th ed.; IBM Corp. Released: New York, NY, USA, 2019.

31. Kuder, G.F.; Richardson, M.W. The theory of the estimation of test reliability. Psychometrika 1937, 2, 151-160. [CrossRef]

32. Pearson, K. VII. Note on regression and inheritance in the case of two parents. Proc. R. Soc. Lond. 1895, 58, 240-242.

33. Ward, J.H. Hierarchical Grouping to Optimize an Objective Function. J. Am. Stat. Assoc. 1963, 58, 236. [CrossRef]

34. Alonso Tapia, J. Evaluación de la motivación en entornos educativos. In Manual de Orientación y Tutoría; Álvarez, M., Bisquerra, R., Eds.; Kluwer: Barcelona, Spain, 2007; pp. 1-39. ISBN 84-7197-380-4.

35. Nicholls, J.G. Conceptions of ability and achievement motivation: A theory and its implications for education. In Learning and Motivation in the Classroom; Paris, S.G., Olson, G.M., Stevenson, H.W., Eds.; Routledge: London, UK, 2018; pp. 211-238. ISBN 9781315188522.

36. García Sanz-Calcedo, J.G.; Salgado, D.R.; Cambero, I.; Herrera, J.M. Application of Techniques Based on Reliability for the Improvement of the Teaching of Mechanisms in Industrial Design. In New Trends in Educational Activity in the Field of Mechanism and Machine Theory. Mechanisms and Machine Science; Springer: Cham, Switzerland, 2014; pp. 101-107.

37. Alonso Tapia, J. Motivaciones, expectativas y valores relacionados con el aprendizaje. Análisis empírico e implicaciones para la mejora de la actuación docente en la enseñanza secundaria y en el bachillerato. In Premios Nacionales de Investigación Educativa 2003; Ministerio de Educación y Deporte: Madrid, Spain, 2005; pp. 255-314. ISBN 84-369-3941-7.

38. Robinson, K.A.; Lee, Y.; Bovee, E.A.; Perez, T.; Walton, S.P.; Briedis, D.; Linnenbrink-Garcia, L. Motivation in transition: Development and roles of expectancy, task values, and costs in early college engineering. J. Educ. Psychol. 2019, 111, 1081-1102. [CrossRef]

39. González, A.G.; Salgado, D.R.; García Sanz-Calcedo, J.G.; García, C.C.; Muriel, J.B.; Pérez, O.L.; García, F.J.Á. A teaching methodology for the real-time assessment of students' competencies related to manufacturing subjects using technology based on electronic devices. Procedia Manuf. 2019, 41, 579-586. [CrossRef] 
40. Ruiz, J. Experiencias de motivación a los alumnos de enseñanza universitaria técnica y artística. In Proceedings of the Actas del XVI Congreso Universitario de Innovación Educativa en las Enseñanzas Técnicas, Cádiz, Spain, 23-26 September 2008.

41. Cifuentes Pérez, P.; Meseguer Cutillas, P. Trabajo en equipo frente a trabajo individual. Tonos Digit. Rev. Estud. Filos. 2015, 28, 17-20.

42. Madni, A.M.; Sievers, M. Model-based systems engineering: Motivation, current status, and research opportunities. Syst. Eng. 2018, 21, 172-190. [CrossRef]

43. Park, S.; Kaplan, H.; Schlaf, R. Interdisciplinary flipped learning for engineering classrooms in higher education: Students' motivational regulation and design achievement. Comput. Appl. Eng. Educ. 2018, 26, 589-601. [CrossRef]

44. González-Domínguez, J.; Sánchez-Barroso, G.; Zamora-Polo, F.; García-Sanz-Calcedo, J. Application of circular economy techniques for design and development of products through collaborative project-based learning for industrial engineer teaching. Sustainability 2020, 12, 4368. [CrossRef]

(C) 2020 by the authors. Licensee MDPI, Basel, Switzerland. This article is an open access article distributed under the terms and conditions of the Creative Commons Attribution (CC BY) license (http://creativecommons.org/licenses/by/4.0/). 